\title{
Yin-yang Idea in Architectural Design - Following Rather Than Altering the Objects' Nature
}

\author{
Xi Ye \\ School of Architecture, Planning and Landscape, Newcastle University, Newcastle Upon Tyne, UK \\ Email address: \\ Underfish008@gmail.com \\ To cite this article: \\ Xi Ye. Yin-yang Idea in Architectural Design - Following Rather Than Altering the Objects' Nature. International Journal of Architecture, \\ Arts and Applications. Vol. 3, No. 1, 2016, pp. 1-10. doi: 10.11648/j.ijaaa.20160301.11
}

Received: December 13, 2016; Accepted: January 13, 2017; Published: February 13, 2017

\begin{abstract}
Yin-yang theory is one of the oldest Chinese philosophies whereby the world is constituted of Yin-yang units rather than pure individual elements. A belief arising from this theory is that when Yin and Yang interact with each other, new things will be generated. "Following rather than altering the objects' nature", which has been widely applied in art and craft creation, originally stems from Yin-yang theory. This idea provides a principle of creating new things based on the original situation with minimal alternation. When the image of the new creation matches the object's existing features, the new creation will be born. Red Brick Art Museum, a rebuilt project based on an abandoned factory, adopts the above idea as its design concept. Thus this project could well interpret the idea "following rather than altering the objects' nature". The design concept does not refer to any supposed form or symbolic meaning of the building, but provides a pragmatic approach of design. Existing circumstances have been addressed greatly. When the image of the new space matched with the existing conditions of the building, transformation strategies would be created, and the rebuilding process would be pushed forward. The ultimate building form is not determined at the very beginning. Building form is not the purpose of the design, but acts as the consequence resulting from the way of dealing with actual problems throughout the design process.
\end{abstract}

Keywords: Yin-yang Idea, Following Rather Than Altering, Objects’ Nature, Red Brick Art Museum

\section{Introduction}

Yin-yang theory is the first written idea found in The Book of Changes (Yijing / I Ching) in Chinese philosophical history. The Book of Changes is the ancient divination text and the oldest of the Chinese classics and is seen as the root of all Chinese philosophies, including both Confucianism and Daoism. The idea of Yin and yang has an influence on Chinese social ideologies, such as in the way of coping with living problems and interpersonal relationships or building houses and creating art works. The article will firstly provide key ideas about the theory of Yin and Yang, especially the belief that when Yin and Yang interact with each other, new things will be generated.

Therefore, on the basis of Yin-yang theory, a design project will be introduced as to interpret how Yin-yang theory has impact on contemporary architectural design. Red Brick Art Museum in Beijing, a rebuilt project based on an abandoned factory, brings the concept "following rather than altering the objects' nature", providing a principle of creating new things based on existing circumstance with minimal alternation, which has been widely adopted in artistic and craft creation traditionally. This article will then explain how the design concept is related to Yin-yang idea by looking at detailed design, particularly how the object's existing nature and the image of new creation make a Yin-yang unite, how the two are matched, and how the interaction of the two gives birth to a new design.

In this project, the pragmatic thinks are engaged in the design concept, as the concept is about a pragmatic way of designing. Therefore, this project is questioning such a design approach that always attempts to find symbolic meaning of a building and tries to present the exact intention of the building form at the very beginning; on the contrary, the design concept encourages a pragmatic approach of designing that sees building form as the consequence of coping with actual problems over design process. 


\section{Yin and Yang: the Basic Unit Constitutes the World}

The Book of Changes conveys that the basic unit constituting the world is not a pure element but a dual mixture of Yin and Yang. They are the opposite principles of nature but they match and are tightly connected to each other. Everything in the world has both Yin and Yang characters which is seen as the nature of the universe [1]. The heaven has both coldness and warmness, the earth has both hardness and softness and the human being has both humanity and justice. According to the Commentary of The Book of Changes, the law of changes in the world is caused by the interaction between Yin and Yang, which is the first evident metaphysics in the history of Chinese philosophy [2]. ${ }^{1}$ This metaphysics is an intangible law that all things and beings in the world must abide by.

The Chinese character Yin (阴) means shadow, whilst Yang (阳) means sunlight [3] If we put an object under the sun, usually, it will be half in light half in shadow. Light and shadow are opposite, but no matter how we put the object under sunlight, there are always two parts that jointly cover the object's surface. The basic skill of pencil sketch is to understand the light and shadow relations of an object. Usually, there is a definition line between the light part and the shadow part, which plays a decisive role in the pencil sketch. Only by dealing with the relation of light and shadow properly can the object be well presented in the drawing. In this sense, Yin-yang concept can be simply understood by a pencil sketch.

\subsection{Opposite and Indispensable}

The light-shadow relation in sketch implies that Yin and Yang are opposite but consistently united. Light (Yang) and shadow (Yin) seem opposite, but light needs shadow to have it defined while shadow needs light to have it emphasized; either of the two can define itself without the other, and they must join together to present the appearance of the object. If there is no opposition, it would neither identify things between each other nor categorise things into Yin or Yang. However, it does not mean one thing should be absolutely in Yin category or absolutely in Yang category [3]. Yin and Yang are relatively opposite. If a son is compared with his father, the son is Yin and his father is Yang; but if the son is compared with his wife, he is Yang and his wife is Yin. Again, if skin is compared with viscera, skin is Yang and viscera is Yin; but if upper half of the body compares with lower half, upper half is Yang while lower half is Yin [4]. Therefore, it is impossible to categorise one thing in absolute Yin or Yang, as one thing depends on its counterpart to have it defined, and one thing could have both properties of Yin and Yang, which are changeable according to time and situation.

Yin-yang idea is the plainest and natural philosophy that has

1 The Book of Changes is made of two parts: I-Ching 易经 (the main Text) and the Commentary of I-Ching 易传. In the Warring states period (500-200BC) a book of commentary written by Confucius was published known as "Yizhuan" based on the philosophical analysis of The Book of Changes. originated from the early stage endeavours of understanding the universal laws of the cosmos, which is based on the most intuitive perceptions and experience of everyday life of Chinese ancestors. According to Yin-yang idea, the duality is the basic feature of universe [5]. The features of duality that were discovered thousands years ago by Chinese ancestors can also be discerned in the present world. This duality is still part of common sense for the Chinese people, such as duality of bright and dark, day and night, waxes and wanes of the moon, male and female, mental and body, happiness and sadness, good fortune and bad fortune, flower and leaf, mountain and water. This feature of duality is the essence of Chinese paintings. When Chinese artists are creating landscape paintings, they will not focus on mountain or water respectively, but they treat mountain and water as a united whole-drawing the mountain and leaving the water area blank will then bring a sense that there is a stream flowing through a mountain. Mountain and water are matched as a Yin-yang unit in a Chinese painting. It only needs to outline the mountain and the water will be presented up simultaneously [6]. Therefore, in a Chinese painting, it takes the relation of mountain and water similar to a figure-ground relation in which the two are harmonious opposite-partners as each of the two needs the other to present itself out. It is difficult to distinguish the figure from the ground. Furthermore, Chinese traditional architecture considers the relation between emptiness and solidness as being of vital importance in spatial structure, which somehow corresponds to the relation of Yin and Yang [4]. The buildings surrounding courtyards are solid while the courtyards enclosed by buildings are empty. Usually in a house, there is a series of courtyards embedded in a series of buildings. Emptiness and solidness interact and are involved with each other in the architecture, following the overall law of harmony of nature.

\subsection{To Change and to Generate}

The Book of Changes claims everything in the world is ever changing, transforming and recycling. Yin and Yang do not keep stable permanently, but are always tending to transmit to their opposite sides [4]. There are numerous phenomena in everyday life that could prove the idea of the eternal change, such as the recycle of day and night, the alternation of seasons, and the aging of human life, the metabolism of living organism, the replacement of good fortune and bad fortune and so on. Chinese traditional architecture is mainly constructed by wood, no matter for royal palace or dwellings, temples or business market, which is different from western stone architecture for the sake of pursuing the sense of permanence. Chinese wooden buildings are not laboriously built to be permanent but are treated as if they are alive. Their design is flexible to embrace aging problems caused by time and to embrace changes caused by the growth of families inhabiting these structures. However, it has to be pointed out that the notion that things have no absolute finality does not mean everything is proceeding towards one direction all the time, but means that things have their extreme points or boundaries. When they reach their extremes, they will turn 
back to the opposite directions [5]. For example, it is believed in The Book of Changes that after the extremely dynamic, the static will come; after storm, calm will come; after extreme misfortune, good fortune will come.

There are generally two types of changes - one of them is caused by the attraction and interaction between Yin and Yang, so that new things will be born and good fortune will come; the alternate situation results from the divergence between Yin and Yang, such that things will go towards bad fortune and an inharmonious situation [2]. Hence, all changes depend on whether or not there is communication or attraction between Yin and Yang. When Yin and Yang are attracted to each other, and get interacted, there will be new things given birth, just as if there is attraction between male and female; after mating, new life will be born. However, if Yin and Yang stop to interact, there would be no changes anymore; the world would stop to generate new life and things will go extinct soon. Therefore, the fundamental motivation of continual generation of new life is the interaction between Yin and Yang.

\section{Following Rather Than Altering the Objects' Nature - Yin-yang Idea in Design}

Understanding everything in the light of Yin-yang unit has great influence on Chinese culture. One of the ideas, following rather than altering the objects' nature, which has been widely applied in artistic and craft creation, stems from the Yin-yang theory. Following objects' nature does not mean sticking to one inflexible rigid rule. The essence of "following" is about generating new things according to existing circumstance of an object, no matter in painting, gardening, poetry, craft, and architecture. Circumstance both restricts and inspires new creation, and new creation might be the only outcome that is most suitable for that particular circumstance. If circumstance is Yin, the picture conceived in artist's mind is Yang. When Yin and Yang match, new things will be born. This approach of applying Yin-yang idea in artistic creation tears down the boundary between concept and practice. No abstract concept is pre-formed before reaching any actual practice. Concept should be established as a means of making the best use of existing situations. Once the imagined picture and particular circumstance match, a new creation will be generated. A painting depends on the painting materials and what the artist wants to express; a poem depends on the language the poet uses and the poet's emotion, and gardening depends on existing conditions of the site and the pleasure the garden aims to provide. When painting materials match the artist's anticipated expression, when verse matches poet's emotion, when conditions of the site match the anticipated function of the garden, artistic creations will be born.

There is a special way of painting in Song dynasty (960AD-1279AD). Painting work starts not with drawing materials but by creating broken walls. An artist in Song dynasty, Song Di, summarized three steps for this special way of painting [7]. First, the broken wall has to be observed. As the broken wall is created randomly by throwing mud freely onto the wall, the appearance of the wall is similar to some character of nature. Observing the broken wall, one could discover a natural mountain and water, similar to mountain and water in real nature. Second, imagining what the drawing would be like. This is the step of matching existing conditions and the imaginary image - artists conceive ideal images in their mind according to the images from the broken wall. The last step is a painting based on ideal images the artists conceived earlier. According to Yuan Ye, Ji Cheng simply introduces some key points for gardening. ${ }^{2}$ The main steps of gardening echo Song Di's way of painting. Similarly, the first step is examining basic conditions of the site-terrain, trees and plants, existing stones, and waters. Second, picturing possible images - some areas have to be heightened to represent a hill, and some possibly have to be lowered to show a valley; some areas require a rock to be added, and some require having a pavilion on the top. The last step is garden construction according to conceived images, and after those images are completely matched with the conditions of the existing site, a new garden will come into being.

Poet Bai Yuyi brings this method of artistic creation into utensil making. In one of his poems he writes "genius seems as if clumsiness"; he advocates about this approach of creation by stating 'making vessel following the shape of material, genius will be inside' [7]. In Bai's view, talented creation ought not to be an absolute concept coming out of nothing, but ought to take the existing conditions of materials as reference. This seems plain and clumsy, but following nature does not simply equate to completely comply with existing circumstance devoid of any originality; however, it is aiming to achieve "twice the yield, half the work"- the "genius" of what Bai means. According to Bai's poem, there are also three steps for utensil making, responding to painting and gardening. Analogical to Song Di's wall observation and Ji Cheng's site examination, the first step for utensils making is material investigation. Following the analysis of existing circumstance of material, the second step is, again, conceiving ideal images based on the requirement of the utensil and matching images with material conditions. For example, when the carpenter finds a timber from a forest that is straight on one side but curved on the other, he might have a decision that the straight part is probably suitable for making a bean for building and the curved part would be used as a wheel for carriage [8]. The last step, certainly, is working on the utensil and making the image comes true. Beam and wheel are made following the character of the timber rather than dominating and changing the natural features. According to Bai Juyi, the gist for image matching is "following rather than altering the objects' nature", while the ideal result of matching is "Twice the yield, half the work" [8]. The carpenter does not change any nature of the timber but he makes best use of both characters of straight and curving from one timber. Carpenter's work responds to the

\footnotetext{
2 Ji Cheng was a Chinese landscape garden artist in the $17^{\text {th }}$ century. His book Yuan $Y e$ was the first scholarly work dealing with landscape gardening in Chinese history and it still acts as a manual for those who are interested in Chinese classic gardens and the study of the art of Chinese landscape gardening.
} 
rule of "following rather than altering the objects' nature". At the meantime, the carpenter matches the nature of the timber with the required qualities of a beam and wheel, which achieves "twice the yield, half the work".

Reliance on natural or existing circumstance is widely applied in artistic creation and crafts making in Chinese everyday life. If we bring this principle into architectural design, matching the nature of the existing site with an ideal design image, we will have a building that will take into best consideration the pre-conditions and will result in "twice the yield, half the work". One architectural project, The Red Brick Art Museum, attempted to incorporate the idea of reliance on natural means as its design concept as well as its design approach, on the basis of following Bai Juyi's verse "the vessel should assume the shape of the material". According to a personal interview with the designer (Yugan Dong), the author found that the concept of this project, following rather than altering the objects' nature, is basically rooted from Yin-yang idea. But the existing literatures could not provide an articulated statement on how the design exactly reflects the design concept (or design approach), how Yin-yang idea is embodied in design over the whole design process, and they also lack an affirmation on the significance of the engagement of pragmatic thinks in a design concept - the way of having meaning from a pragmatic stance rather than symbolic purpose. All of above ambiguous points are worthy to be clearly clarified.

Red Brick Art Museum is a rebuilt project based on an old abandoned factory located in the northeast suburb of Beijing. The rebuilt project is about 4000 square meters and the project was accomplished in 2011 [9] (Figure. 1). All of the exterior walls are built up by piling up red bricks and there is no cutting or re-shaping of any single brick; this is why the building is named as "Red Brick Art Museum" (Figure. 2). Dong describes the current situation of the factory as "simple, crude, and huge" [7]. There is almost no interior partition wall. Exterior walls are exposing in air with $6 * 6$ m's big openings arraying in a line along two long walls; one of the walls is facing the main street; another is facing an inner blank area. These big openings make existing conditions far from what is required as an exhibition building that should provide sufficient interior displaying walls for art works. Above the simple steel-frame ceiling, there is a sunroof with strip-shaped skylights, covering from south to north. Although the sunroof provides good natural light, yet direct light through the sunroof would bring trouble into exhibitions (Figure. 3).

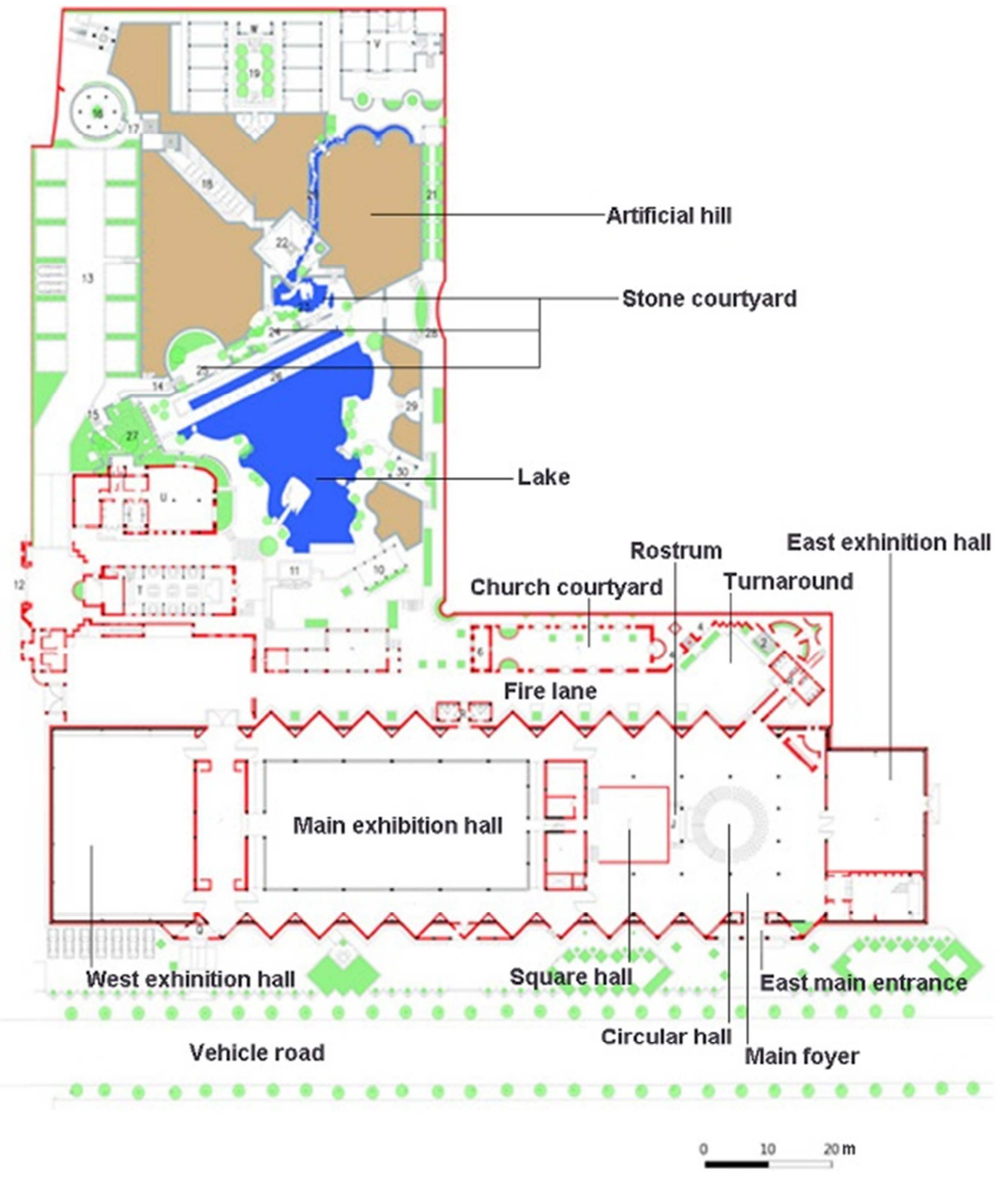

Figure 1. Ground Floor Plan. 


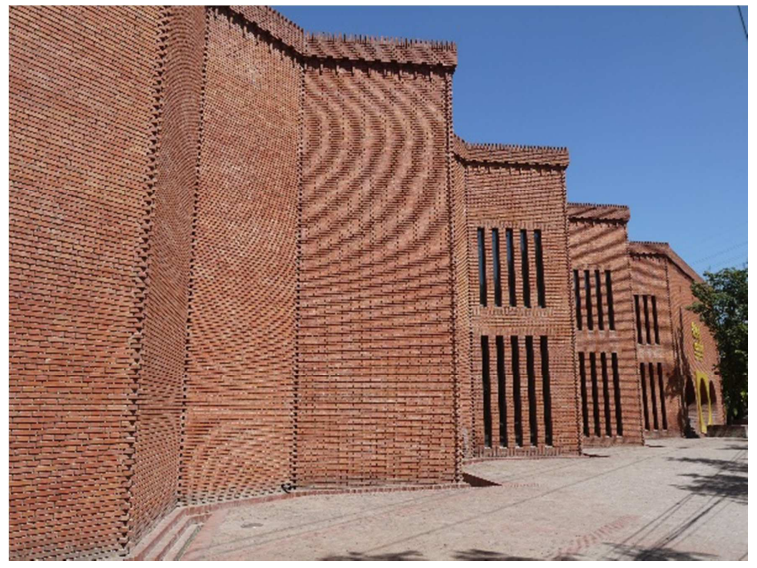

Figure 2. The exterior wall.

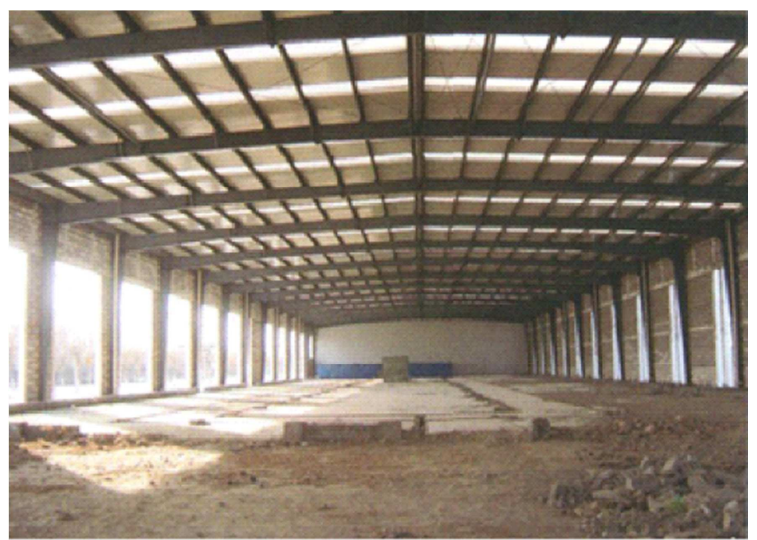

Figure 3. The old abandoned factory.

\subsection{Transformation of Exterior Walls}

Transforming exterior walls is the first major difficulty for the project, and how to take ingenious use of the existing walls would present a key response to the concept of "following rather than altering object's nature" and "twice the yield, half the work". Successive openings on the wall are a tough problem, as what the art museum needs is a closed exhibition wall and diffused light. In order to have a continuous exterior wall, Dong does not want to simply fill the existing openings or rebuild completely new walls straightforward to replace the old walls, because to him, this is the way of making rather than designing [10]. Because the architect has decided to have a big exhibition hall in the middle of the steel shelf, there would be a 5-meter-wide corridor between the existing exterior wall and the hall. However, 5-meters-wide is not enough for displaying artistic works more than 5 meters high, as according to the body scale, the ideal distance for watching an art work is 1.2 to 2 times as the height of the work between the viewer and art work. Therefore, there comes up a contradiction-if the architect simply compresses the middle exhibition hall to make enough room for corridor, it would reduce the space for the main exhibition hall; the corridor and the middle hall are competing for space. Finally, the architect has worked out a solution to resolve all problems without changing anything of the existing exterior walls.
A series of right triangles are applied zigzagging through existing openings. Legs of triangle both meet outside and inside of the existing walls. As legs of all triangles lean against the edges of the walls between big openings, they form triangular chambers in the corridor enclosed by legs and existing walls, which perfectly wrap up steel columns and water pipes next to existing walls, and triangular spaces are also formed among legs and existing openings, which will serve as display spaces (Figure. 4). However, these are not the only benefits those zigzag triangular walls offer; more benefits are generated unexpectedly. First, displaying space in each existing opening area are doubled by adding right triangle, compared with simply adding flat walls to fill in existing openings. This benefit is especially important for exhibition buildings. Second, triangular spaces repetitively appear along the corridor providing a better interior spatial experience than flat walls. Triangular spaces help both maintain visual continuity of the corridor and keep individual triangular space semi-independent (Figure. 5). Third, triangular walls expand the sight distance of the corridor from 5 meters to nearly 7 meters, which meets the standard of a good exhibition space and it gives rise to a comfortable bodily experience. Fourth, triangular displaying spaces provide a good room for skylights on top of the spaces (Figure. 6). Skylights are installed on flat roofs over displaying spaces, which are invisible from outside, instead of cutting openings on exterior walls. Usually, skylights alone are able to function well for exhibition without assistance of artificial lights [7].

Existing walls with a series of big openings are retained completely and made most use of. Old walls between openings are retained as exterior walls and at the same time play a role together with right triangle legs in forming triangular chambers to cover steel columns and water pipes. New built zigzagging walls, going back and forth through openings, leave the existing exterior walls unaltered, but generate more exhibition area, wider sight distance, better light quality as well as spatial experience. All of these represent the idea "following rather than altering object's nature". The renovation relies on the conditions of old materials, aiming to meet the requirements as an exhibition building, but at the same time, unexpected benefits are achieved. It seems the aim to resolve pragmatic problem sometimes acts as a cutting point, but with the proceeding of the scheme, some more advantages might come up. Those advantages may all reside at one small renovation. If one renovation is implemented and more advantages are brought about, this renovation might be a genius approach, one that achieves "twice the yield, half the work". The interaction between old walls and new zigzag walls seem analogous to the interaction between Yin and Yang. The existing wall is Yin while the new built wall is Yang. Conceived images of the new building are generated based on existing conditions as well as based on the purpose of matching existing conditions. The function of interaction is to generate, such that the interaction between old and new walls means to generate new things likewise and thus "twice the yield" is generated and the new 
building facade is formed simultaneously.

The form of facade is not designed in advance to meet visual expectations before engaging in pragmatic problems. Rather, it is formed through practically dealing with particular problems in temporal circumstances. The form is reasonable only in this case, and cannot be borrowed or applied in any other cases, since it is the product of the interaction between this particular circumstance and the architect's imagination. The form of facade does not follow any abstract self-generated concept, but rather follows an idea of design method, "following rather than altering the objects' nature, making vessel by virtue of the shape of the material", originated from the most ancient idea of Yin-yang interaction. The generation of the facade relies on a design concept that is borrowed by the architect from traditional philosophy of Yin and Yang. This design concept lays all attention on pragmatically resolving concrete problems in specific cases in everyday life; thereby, the form of the facade is the consequence of the design process.

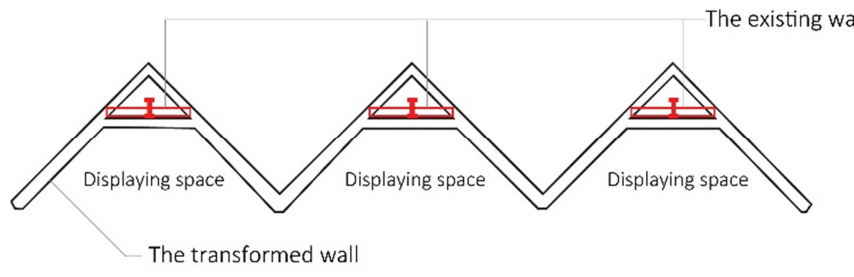

Figure 4. The idea of the transformation of the exterior walls.

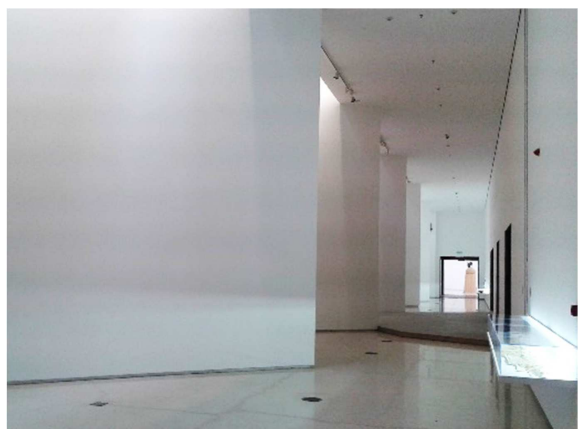

Figure 5. The corridor between the main exhibition hall and the exterior wall.

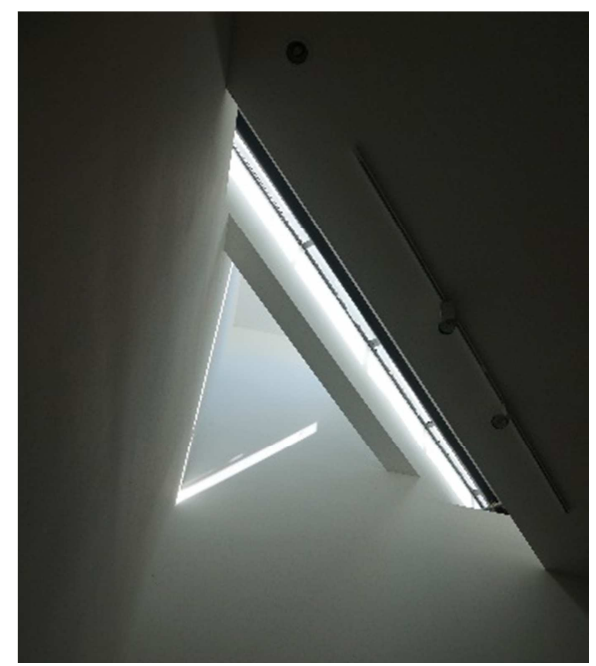

Figure 6. Skylights over the displaying space.

\subsection{Square Hall and Circular Hall}

Through the east main entrance, there is a main foyer area with the most complicated design requirement: a public welfare hall-Square hall, a press conference for temporary exhibition - Circular hall, a small report room, a bar and a reception room, and there is a loft over the main entrance foyer for office or an assistant's use. Generally, within this nine-metre-high steel shelter, there are two ways to win more space, digging to lower space and expanding to upper space [9].

The small report room requires all artificial light and good soundproofing, such that it is better to put it underground. It sinks three metres below the ground. Because of the strong resistance of underground water, three metres is the lowest level it could reach. But the architect is concerned that a three metre clearance height is not enough for a report room and therefore he decides to set up the ceiling on the 1.2-metre-high crossing beams; thereby, the ceiling is elevated to 1.2 metres above the ground level. After paving with red bricks over beams, this arresting 1.44 metres high platform is just suitable as a stage for performance. Hence, the architect aims to make this brick-piled platform function as a displaying stage for the public welfare hall as well as a huge stair landing linking the ground floor and the loft [7]. As the public welfare hall is shaped like a square, it is simply called the Square hall (Figure. 7).

However, as the platform is at a height of 1.44 metres above the ground floor, it brings to question attracting visitors and inducing them to go up to the exhibition stage. Dong notices a phenomenon whereby visitors are apt to be attracted by previous visitors [7]. However, it is hard for exhibition spaces to do so, since art works are usually displayed in completely closed spaces, which blocks sight when coming from outside. Therefore, opening up the closed exhibition wall to enable sight communication would be a good solution. Therefore, instead of piling up bricks all the way from foot to top, the wall is suspended over the platform, leaving a continuous horizontal slot all around the platform, and the slot is exactly at eye-level to visitors standing on the ground floor. This horizontal slot ingeniously eliminates the closure of the Square hall and makes room for sight interaction between the Square hall and the main foyer. The final decision for the height of the slot is $40 \mathrm{~cm}$, as this is the maximum height of the slot without guardrails. Once visitors access the Square hall, it is interesting to see moving feet through the $40 \mathrm{~cm}$ high slot between the wall and the platform in the main foyer, which draws attention and attracts visitors' interest in going up to the Square hall.

How to access the report room from the main foyer turns out to be another question. A sinking space is created in the middle of the main foyer, which sinks 1.26 metres from the ground floor, leading to the report room three metres underneath. The sinking Circular hall (Figure. 8) is enveloped by a circular wall at the loft level and is illuminated by natural light through the roof and through the hollow surrounded by the circular wall [7]. This sinking space functions as a press 
conference room for a temporary exhibition. The steps going to the bottom are in random order, which can be used for seating, relaxing, as well as a children's playground. Opposite to these random steps, there is a brick-piled rostrum next to Square hall, 0.9 metre higher than the ground floor (Figure. 9). The space between the heightened rostrum and the lowered sinking Circular hall is enough for people to access the small report room hidden underneath Square hall. Thus, the sinking space also functions as a big stair landing linking the ground floor to the small report room.

It seems the architect does not attempt to think about the scheme from a macro-scope, but he focuses on problems one by one and provides solutions according to temporary circumstances in the process, and at last reaches the final form of the interior space. The requirements of artificial light and sound insulation of the small report room lead to the first solution, that is, putting the room three metres below the ground floor under the consideration of the impact of underground water resistance. After putting the report room underground, it encounters another problem of insufficient clear height. However, after the ceiling of the report room has been heightened, it causes access difficulty for the Square hall; thus, a suspended wall resolves problem. An access to the small report wall from the main foyer is required, such that a sinking space is required to serve as a stair landing. However, the sinking space is expanded and is shaped as a circle, and functionally becomes a press conference area as well as a cafe when it is available. The challenges the architect comes across during the design are updating the design process; each solution to a certain problem generates new problems and new opportunities. The architect, all the time, takes the latest circumstances into consideration for the design. Therefore, the images conceived in the architect's mind are changing throughout to match the changing circumstances, all through the design process; and the form of the interior space keeps changing with the change in the images, until all problems have been solved. The concept of the design is seeking out problems that exist in current circumstances and working out solutions based on opportunities that also reside in the prevalent circumstances. In addition, each solution has two or more roles. The platform of the Square hall functions as the ceiling of the small report room and the linkage between the loft level and the ground floor, besides acting as a public welfare exhibition space. Similarly, the Circular hall is a place for press conference, and is also a linkage between the small report room and the ground floor, a public rest area as well as a cafe occasionally. These multifunctional solutions, again, point to the principle of "twice the yield, half the work".

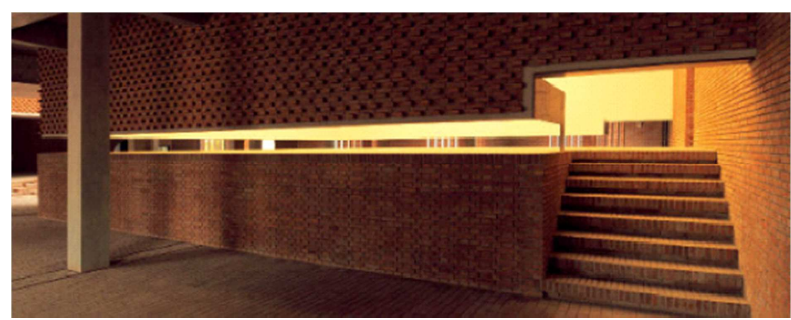

Figure 7. Square hall.

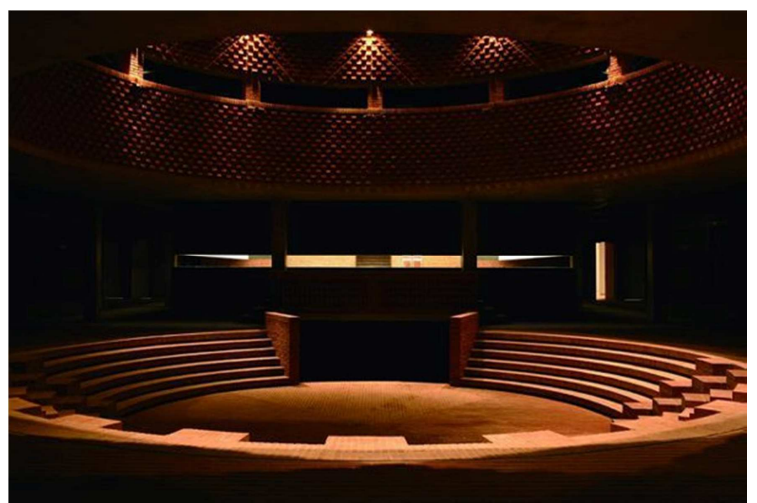

Figure 8. Circular hall.

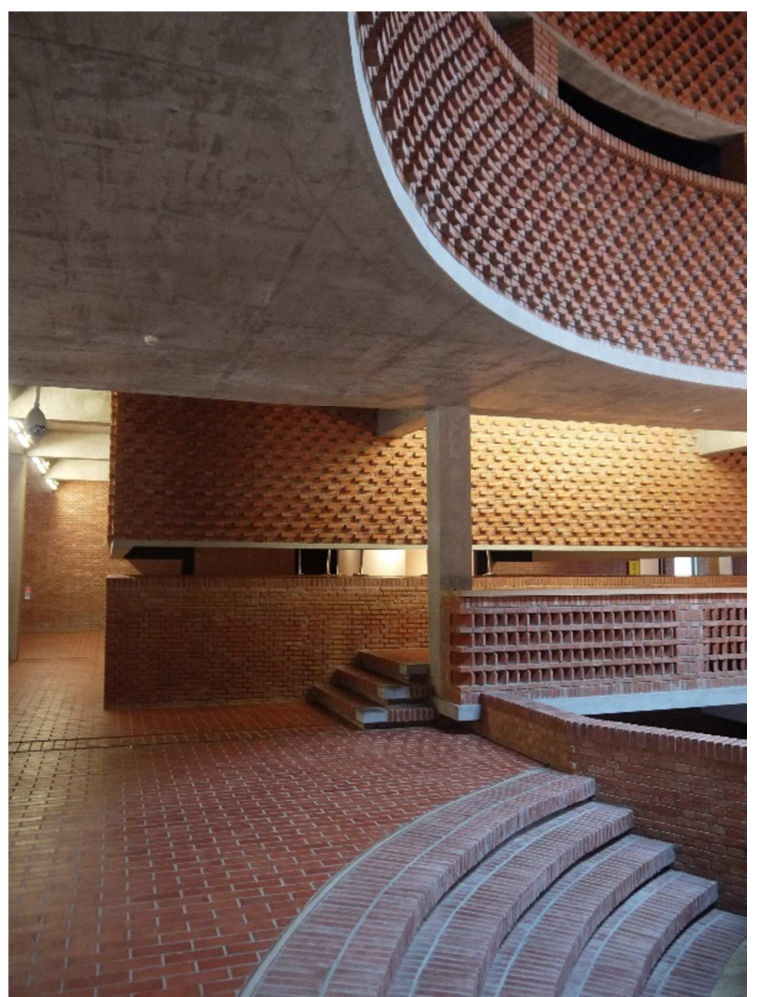

Figure 9. Looking towards Square hall from Circular hall.

\subsection{Church Courtyard}

There is plenty of open space north of the museum. It is also a part of the project, including a small and narrow space on the northeast side and a bigger square space on the northwest side. Landscape designers are involved in the design. They have started to work on this space since 2008, and construction is still ongoing.

The design of this large courtyard north to the museum still relies on "following rather than altering object's nature". The design of each object is tending to approach a certain image according to the existing situation. Those images refer to either natural experience or the intention of resolving real problems. Dong criticises the museum for its over-closed appearance, which partly attributes to the separated phases of design of the courtyard and the building - the courtyard design comes second to the building design. Dong thinks the opportunity to establish a good interaction between building 
and courtyard has been missed [7]. Therefore, when he sets out for the courtyard design, he seeks other starting points as circumstances to stand on instead of merely taking reference from buildings.

The middle courtyard is a small area northeast to the building, connecting the northwest big garden and the art museum. It is a narrow space but required to have a four-metre-wide fire lane and $12 \times 12$ metre turnaround for a fire engine, according to the fire safety norms. The architect starts by looking for solutions to meet fire safety requirements. The four-metre-wide fire lane can possibly be put outside along the north exterior wall, while the $12 * 12$ metres turnaround for the fire engine can be placed at the east end of the lane. However, the east-west fire lane renders the rest of this narrow place much narrower. Thus, narrowness has become a strong character of this place. Architect takes this character as "the object's nature", attempting to follow and reinforce the sense of narrowness rather than altering this feature.

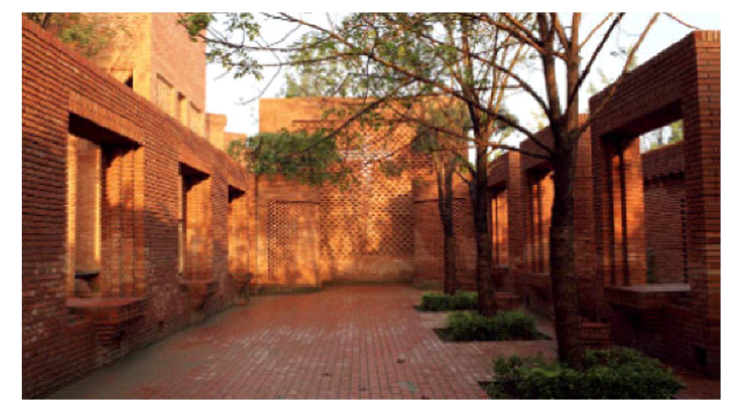

Figure 10. The church courtyard.

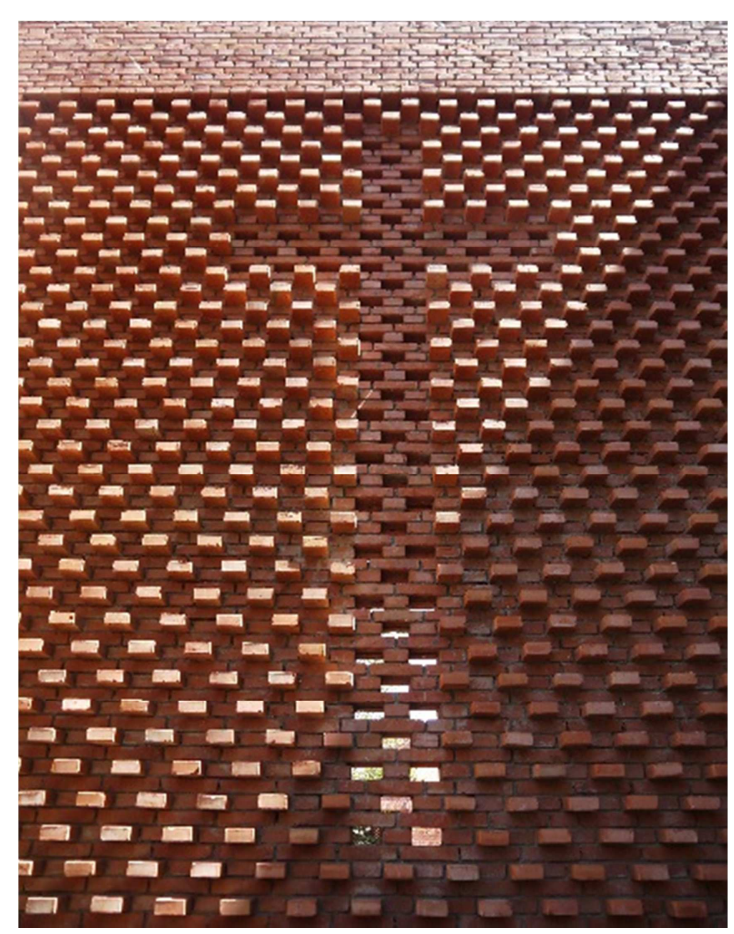

Figure 11. The wall with a cross.

Basilica plan attracts architect's interest, since the sense of narrowness it expresses could be possibly adapted to the current character. Hence, a small church courtyard placed north to the fire lane is being conceived (Figure. 10). As Dong explained, some years ago, he designed a church but did not have the chance to build it. This time, he finds that it is a good chance to put the scheme into practice [7]. Therefore, he put the Basilica church in the remaining narrow space. However, because constructing buildings other than the museum is not allowed, the roof of the church is removed and the walls are left, creating an east-west church-like courtyard. A circular shrine is designed at the east end of the church, but a wisteria is enshrined instead of an idol or a cross. At the west end of the church, opposite to the shrine, a six-metre-high wall is set up. Standing right in front of the high wall, a cross will be displayed out (Figure. 11). The cross is shaped by drawing selected bricks out of the wall, and standing directly opposite the wall when the light comes through the cross, the hollow cross will be revealed completely. According to Dong, the cross is intended to maintain the image of the church, as a compensation for the loss of the roof [7].

This courtyard tends to occasionally serve as an out-door café, as the accessory for the indoor one. There are a number of foreigners living nearby; therefore, the idea of a basilica style courtyard is also a means of attracting more foreign visitors. To reduce the sense of inhumanity of the church, walls are only set at 3.3 metres height, and brick tables are added to window sills - the window is not only for viewing, but is also usable. In addition, the basilica style courtyard is planted with big trees opposite to those window openings, so that trees are visible from outside through windows and trees, and will help the cafe function better in summer time.

Brick tables upon window sills in the south are planned to be used as displaying tables for sculptures. Opposite to the south wall cross fire lane, the areas between triangular masses outside the north exterior wall of museum are earmarked to plant trees, and set a series of square-shaped tree grates. These tree grates could also be used as displaying tables for sculptures. Two rows of displayed sculptures along the two sides of the fire lane are designed to achieve an image of an open-air sculpture gallery, but unfortunately, tree grates have been removed and the image of the gallery is partly lost.

The building-like courtyard finally arouses the client's desire to convert into an report room (Figure. 12), to resolve the problem of lacking report spaces for the museum. Hence, since 2014, the transformation project around the roof of the church has been started. Solutions to transformation also rely on the current circumstances that the previous design offers, rather than creating something completely new. According to Dong [9], the transformation is not about individual building only, but about the linkage between the spaces around the church. He plans to take the newly added roof as intermediate to link the loft level of the museum, water tower at the west end of the church and the small garden at the east side of the church. One bridge is set going across the loft level of the museum to the east end roof of the church, and winding down to the small garden at east side of the church (Figure. 13). Another bridge, at west end of the church, links the water tower and a secluded narrow path attached to museum exterior 
wall leading to the ground level. The two bridges are connected by the walkable roof over the previous church courtyard.

The V-shape roof results from a multifunctional consideration (Figure. 14). On the one hand, as the roof serves as the connection between the water tower and the loft level of museum, there should be a flat path across west end to east end on the roof. Valley of the V-shape offers the opportunity to accommodate a path. On the other hand, V-shape beams not only support the roof as structural frames, but also allow natural light into the report room through the space between two beams at the top of the side walls.

There is nothing generated absolutely by itself but by compliance with the conditions at that moment. The architect takes fire safety requirement, a technique indicator, as the starting point, and the construction of the fire lane makes the originally narrow space become narrower. Thus, the architect tends to use this spatial character by adding a basilica style courtyard. On the one hand, the basilica plan could be properly adapted to this narrow and long space; on the other hand, the basilica spatial form could express and reinforce the original character of the space. As no other building is allowed to be built, the roof is removed and it turns out to be a courtyard with a basilica style plan and walls. Thereby, a cross is smartly designed in a high brick wall to maintain the sense of church, and finally, this non-roof church is planned to be an ideal place for an outdoor cafe. As a result of being a cafe for everyday use, the inhuman character of the church has been erased. Thus, the architect has changed the church courtyard into a more human place by virtue of plants and human-scale brick furniture. Finally, the architect finds an opportunity to achieve an image of sculpture gallery with the help of brick tables and tree grates on the other side. However, unfortunately, the courtyard has been transformed into a building, but the transformation project is still following the rule of making best use of existing conditions and deriving the most benefit possible. Consequently, the same as the museum, the architect's creation has been generated based on previous a creation. Each step is determined according to its current circumstance. Creation is updating with the updating of current circumstance. Any creation is not an independent entity, but the existence of anything is interpreted and justified by others who shape it.

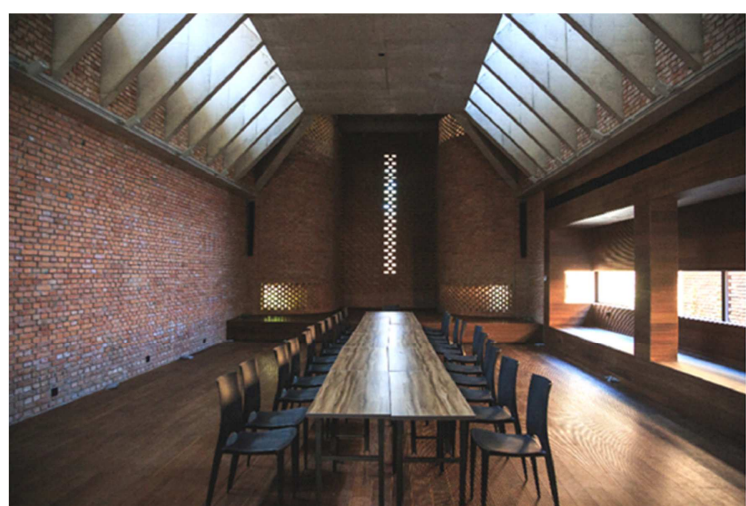

Figure 12. The transformed report room

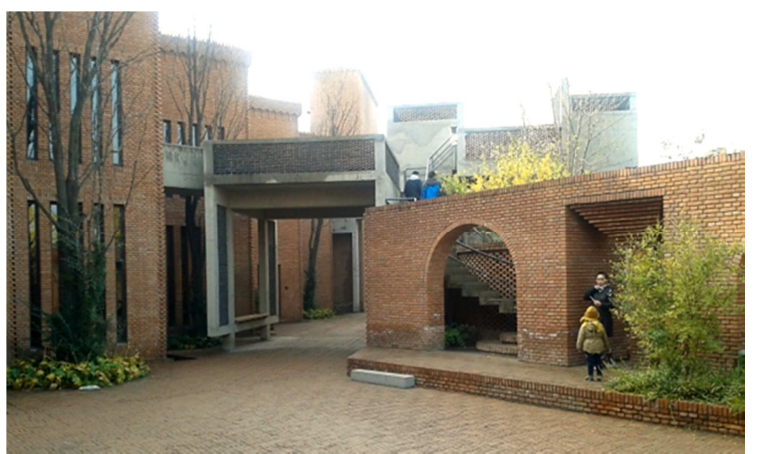

Figure 13. The bridge connecting Museum and the roof of the church courtyard.

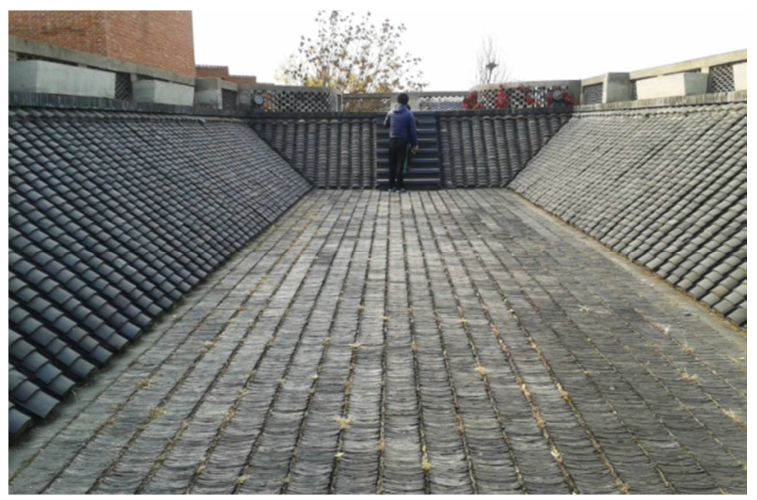

Figure 14. The newly-built V-shape roof.

\section{Conclusions}

All the way throughout the design process, the current circumstances of the objects and images conceived in architect's mind are matched as a Yin-yang unit. When a particular circumstance meets a suitable image, they will soon get matched and a proper solution will be worked out so that a new creation will be generated. As the circumstance is updating, the design work is proceeding, thus the final form is being shaped up. Echoing the principle that there is nothing absolutely Yin or absolutely Yang but things are both Yin and Yang, in the Red Brick Art Museum, one object is always tending to have two or more characters. For instance, the roof of the church courtyard also serves as a high walk; the platform of the Square hall serves as the roof of the report room underneath and the stage for exhibition as well as the stair landing for upper floor; the zigzagging walls that expand watching distance for a better exhibition space also function to cover old water pipes, divide individual displaying spaces as well as allow natural light to come through, without cutting openings on the exterior walls.

Red Brick Art Museum is following Bai Juyi's two requirements for the craftsman as its design concept, "following rather than altering the objects' nature" and "Twice the yield, half the work". "The objects" nature' in this design refers to existing exterior walls with successive big openings, spacious interior space under the steel shelter, the scale of open air spaces, the function and safety requirements as a museum, client's preferences, surrounding buildings and landscapes, materials available from local, and the updated 
situations over design process. "The objects' nature" helps the architect to construct possible images for new space of the museum, thus the nature serves as standing base and gives possible justifications for design and thereby renders the design reasonable and reliable. "Twice the yield" in the design is reflected by multi-purpose of new walls, heightened Square hall, lowered Circular hall, added roof of church courtyard, and so on. These multi-purpose solutions come from solving certain problems, but when new forms are generated, they are found out to be beneficial in other terms. Creation follows the nature of existing objects, such that "twice the yield, half the work" can be realized, as new creation is not worked out from nothing, but based on existing objects. Existing object is being used and new thing is being created at the same time.

Therefore, the matching between existing conditions and conceived images gives rise to the birth of new creation, analogous to the principle that once there is interaction between Yin and Yang, there will be new things generated. The design concept is about a pragmatic approach of craftsmanship, a method of coping with concrete reality rather than an overhead conceptual ambition with clear intention of ultimate building form at the very beginning. However, the ultimate building form presents itself at the end of the design, after the concept has been fully delivered and problems have all been resolved through the design and construction process. The building form is the consequence of the design, rather than the purpose. In this sense, the design of Red Brick Art Museum well echoes what Frampton called "ontological aspects of tectonic form" [11]. The ontological tectonic form refers to the core of a building that is "simultaneously both its fundamental structure and its substance", whilst the representational aspects emphasise the skin of a building that tries to represent a sort of symbolic meaning. Red Brick Art Museum does not attempt to present any symbolic meaning, but the meaning comes from the substance of the building itself - the materials, the constructional techniques, the spaces, functional problems, and the design approach that shaped the form of the building.

As a result, the idea that "following rather than altering objects' nature" implies such a mindset in design practice: architecture ought not only about an ambitious slogan-like concept, a perfect image prior to design practice; however, architecture should better be a consequence of pragmatic practice, a result from the managing of temporary and constantly updated circumstances over design process. Therefore, building forms acting as responses to existing circumstances are final answers to architectural meaning. None of the conceptual symbols are necessary to be sought out as to be disguised as architectural meaning.

\section{Acknowledgment}

A particular gratitude should give to Professor Yugan Dong for his interview that greatly helped me in structuring the overall idea of the manuscript. The author is also grateful to $\mathrm{Hao} \mathrm{Xu}$ for his early recommendation to this architectural project and to Massar Alsamraae for his suggestion in the development of the main idea.

The author would like to acknowledge the support of PEOPLE MARIE CURIE ACTIONS: PUMAH (Planning, Urban Management and Heritage) Project (FP7-PEOPLE-2011-IRSES), funded by the European Union Seventh Framework Programme ([FP7/2007-2013] [FP7/2007-2011]) under grant agreement $\mathrm{n}^{\circ} 295045$.

\section{References}

[1] Zhu, Bokun, Works of Zhu Bokun. Shenyang: Shenyang Publishing House, 1998.

[2] Yang, Qingzhong. "On the Dao in the Commentary of the Book of Change," Frontiers of Philosophy in China 2006, vol. 1, no. 4, pp. 572-593, 2006.

[3] Zeng, Shiqiang. The Secret of I-Ching. Xi'an: Shanxi Normal University Press, 2009.

[4] Lan, Yungong. "Yin-Yang Thinking and the Characteristics of Chinese Traditional Culture," Journal of Liangshan University, 1999, no. 1, pp. 79-82.

[5] Dou, Zongyi. "Exploration of I Ching's Philosophical Principle of Dialectical Monism Based on the Enlightenment of Modern Science," Study on The Book of Changes, 1995, no. 3, pp. 71-79.

[6] Bai, Kun. "Brief Discussion of the Idea of Leaving Blank in Chinese Painting and Its Origin," Qilu Realm of Arts, 2008, no. 1, pp. 19-21.

[7] Dong, Yugan. Broken Walls and Ruins, Shanghai: Tongji University Press, 2012.

[8] Dong, Yugan. "Designing According to Circumstances Design for the Red Brick Contemporary Art Museum," Architecture Journal, 2013, no. 2, pp. 44-51.

[9] Dong, Yugan. Heaven and Paradise, Beijing: China Architecture \& Building Press, 2015.

[10] Dong, Yugan. "Image and Setting - Red Brick Art Museum, Beijing," Time+Architecture, 2013, no. 2, pp. 65-70.

[11] Frampton, Kenneth. Studies in Tectonic Culture: The Poetics of Construction in nineteenth and Twentieth Century Architecture. Cambridge, Massachusetts: MIT Press, 1995. 